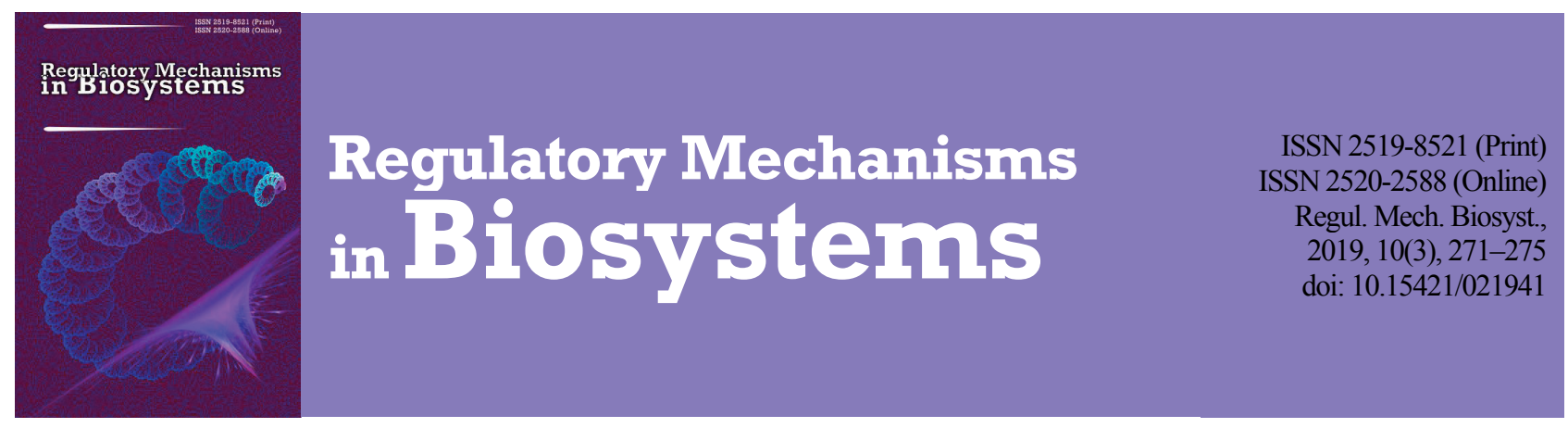

\title{
Genetic aspects of metabolic disorders in pregnant women with pathological weight gain
}

\author{
S. O. Ostafiichuk \\ Ivano-Frankivsk National Medical University, Ivano-Frankivsk, Ukraine
}

Article info

Received 04.08.2019

Received in revised form 01.09.2019

Accepted 03.09.2019

Ivano-Frankivsk National Medical University,

Galytska st., 2,

Ivano-Frankivsk,

76018, Ukraine.

Tel.: +38-050-950-07-70.

E-mail:svitlana.ostafjichuk@ gmail.com

\section{Ostafiichuk, S. O. (2019). Genetic aspects of metabolic disorders in pregnant women with pathological weight gain. Regulatory Mechanisms in Biosystems, 10(3), 271-275. doi:10.15421/021941}

Polymorphism of the leptin receptor gene (LEPR) has been shown to be linked to obesity-related metabolic markers and phenotype. Therefore, we hypothesized that the Gln233Arg LEPR polymorphism is related to metabolic changes in pregnancy and the risk of excessive gestational weight gain (GWG). A total of 97 pregnant women with a singleton gestation were enrolled from April 2016 until December 2018. Genetic variants of LEPR were analyzed by real-time polymerase chain reaction, leptin by enzyme-linked immunosorbent assay, lipid profile, and carbohydrate status were assessed in the first, and third trimesters of pregnancy. The recommended GWG was diagnosed in $34.0 \%$, insufficient in $19.6 \%$, and excessive in $46.4 \%$ patients. Statistical analysis revealed that $20.6 \%$ patients were with AA genotype, $50.5 \%$ - AG genotype, and $28.9 \%$ - GG genotype. The frequency of GG-alleles carriers of the LEPR Gln233Arg gene in the group of excessive GWG patients was 3 times higher compared to recommended GWG patients. Thus, the inheritance of pathological G-homozygotes increases the risk of excessive weight gain by 7 times, compared to carriers of the AA genotype. LEPR GG polymorphism was significantly associated with high levels of triglycerides, total cholesterol, lipoprotein low and very low density, and leptin compared to homozygous A-carriers in the third trimester of pregnancy. In pregnant women with GG polymorphism, the glucose level, insulin level, and HOMO-IR index were significantly increased compared to women with AA genotype in late pregnancy. In the group with excessive GWG, the presence of GG-alleles of the LEPR gene was accompanied by a higher level of hyperleptinemia, compared to carriers of AA-genotype. Inheritance of pathological G-homozygotes was associated with hyperlipidemia, leptin resistance with high leptin serum levels, and increased insulin resistance, which was especially manifested in excessive GWG. In our opinion, excessive GWG can be seen as a marker of the mother's genotype and genetic predisposition to the development of metabolic diseases after delivery.

Keywords: LEPR Gln233Arg polymorphism; leptin; lipid profile; carbohydrate status; insulin resistance.

\section{Introduction}

Overweight and obesity are among the leading global factors that affect the health of the population. The obesity rate is $35.7 \%$ among young people between the ages of 20 and $39,42.8 \%$ among middleaged people between 40 and 59, and $41.0 \%$ among adults aged 60 and older (Hales et al., 2017). WHO reports that obesity is an epidemic on a massive scale: 2 billion adults are overweight and 500 million suffer from obesity, over 41 million children under the age of 5 are obese. In Ukraine as of 2014, the rate of overweight was 58.5\%, and obesity was $28.4 \%$ among women aged $18+$. Over the past 10 years, the rate of obesity among adolescents (15-17 years) per 1000 has increased by 2.5 times (Deren et al., 2018). Overweight women have an increased risk of developing type 2 diabetes, coronary disease, hypertension, metabolic syndrome, infertility, pathology of pregnancy, complicated delivery, overweight in children (Devlieger et al., 2016). In many women, the development of overweight is associated with one or more pregnancies (Farpour-Lambert, 2018). Recently published meta-analysis data confirms that in more than one million women the pathological gestational weight gain (GWG) triggers postpartum weight retention (Goldstein et al., 2018).

Metabolic supplement in weight gain takes place under the influence of endogenous factors. The elevation of production of placental hormones which regulate carbohydrate, fatty protein and water metabolism changes plays an important role in adapting the maternal organism to a new state and providing adequate growth and development of the fetus (Napso et al., 2018). Increased production of contra-insular hormones by the placenta, such as placental hormone of growth, prolactin, cortisol, progesterone, especially in the second and third trimesters of pregnancy, causes a state of insulin resistance. A rapid increase in body weight due to an increase in fat component is associated with the action of metabolically active proteins-adipokines such as leptin, resistin, adiponectin, IL-6 (Logan et al., 2017).

Leptin is a hormone that basically performs a signaling functiontransmits information about body weight to the hypothalamus, reduces appetite and food intake. In the non-pregnant state, the adipose tissue is the exclusive source of circulating leptin. This hormone controls the mass of adipose tissue by stimulating the metabolism of lipids (increases lipolysis, reduces the content of triglycerides in the white adipose tissue, the liver, skeletal muscle and the pancreas, enhances thermogenesis) and is an indicator of the energy supply in the body (Sámano et al., 2017). During pregnancy, leptin is additionally produced by the human placental trophoblast cells. Its concentrations rapidly rise throughout gestation, peaking toward term. It was found that in humans, blood leptin rapidly decreases to non-pregnant concentrations within $24 \mathrm{~h}$ of delivery, indicating that the placenta contributes more than adipose tissue to the rise of leptin in pregnancy (Costa, 2016). In normal pregnancy, the level of placental leptin gradually increases during the gestational period and, as recent studies have shown, plays an important role in implantation, production of chorionic gonadotropin, angiogenesis of new vascular placenta, placental growth, mitogenesis, and protects placental cells from apoptosis (Pérez-Pérez et al., 2019). 
The disorder of adipokine regulation, associated with polymorphisms of leptin or leptin receptor genes, has been shown to be one of the potential risk factors for metabolic changes leading to excessive weight gain. The leptin receptor (LEPR) gene is located in the chromosome of $1 \mathrm{p} 31$ and plays a leading role in the regulation of eating behaviour, body weight, energy homeostasis, and metabolic processes. The result of mutations in the LEPR gene is the formation of inactive forms of leptin receptors that are not able to provide hormonal signal transduction and determine the resistance of target cells to the action of leptin (Maymó et al., 2011). During pregnancy, such patients' placental leptin resistance develops due to syncytiotrophoblast reduced regulation of leptin receptors combined with elevated serum leptin levels (Stacy Tsai et al., 2015). The central leptin resistance is manifested by dysfunctional signaling of leptin and leads to spontaneous development of gestational diabetic phenotype, loss of satiety, hyperphagia, hyperinsulinemia, and pathological weight gain (Tessier et al., 2013).

There are results of several studies aimed at examining interaction of LEPR Gln233Arg polymorphisms with the development of hyperleptinemia, hyperglycemia and insulin resistance in type 2 diabetes (Yang et al., 2016; Sulaieva et al., 2018), obesity (Carlhäll et al., 2016). Despite this, we have not found in the literary resources studies of the role of Gln223Arg polymorphism of the LEPR gene in the genesis of weight gain during pregnancy in women with normal prepregnancy body weight. Thus, in our opinion, the study of the clinical and diagnostic value of the leptin receptor gene polymorphism in the Ukrainian pregnant women cohort is relevant. We can hypothesize that if genetic variants associated with obesity and diabetes lead to a pathological weight gain during pregnancy, then excessive GWG can be a marker of genetic predisposition to the development of further metabolic diseases. The aim of this study was to determine the association of the Gln233Arg polymorphism of the LEPR gene with metabolic changes in pregnant women with pathological GWG.

\section{Materials and methods}

The study is a part of the complex scientific research work "Clinical-pathogenetic ways of reducing the frequency of reproductive health disorders and perinatal complications of women in Prykarpattya" (state registration № 0114U004747). A total of 97 pregnant women with a singleton gestation who visited the antenatal clinics in Ivano-Frankivsk Ukraine were enrolled from April 2016 until December 2018. Patients under 18 years old, and patients diagnosed with multiple pregnancy, severe chronic diseases, overweight, obesity and diabetes mellitus were excluded from the study. All women signed "Informed consent to participate in the study". The research design was approved by the Ethics Committee of the Ivano-Frankivsk National Medical University (No 93/16 from 01.12.2016). 59 (60.8\%) of the examined patients were nulliparous and 38 (39.2\%) were multiparous women. The GWG was diagnosed at the recommended level in $33(34.0 \%)$, inadequate in 19 (19.6\%), and excessive in $45(46.4 \%)$ patients. The average age of patients at the onset of examination was $26.8 \pm 2.6$ years and did not differ significantly between the groups of women with different GWG $(\mathrm{P}>0.05)$. The average height of the patients was $164.7 \pm 5.5 \mathrm{~cm}$ and also did not differ between women with different weight gain $(\mathrm{P}>0.05)$. Prepregnancy weight was $55.8 \pm 5.8 \mathrm{~kg}$, BMI $20.6 \pm 1.6 \mathrm{~kg} / \mathrm{m}^{2}$, which corresponded to the normal weight as defined by the recommendations of the Institute of Medicine in the USA (2009) and the Order of the Ministry of Health of Ukraine No 417 (BMI $18.5-24.9 \mathrm{~kg} / \mathrm{m}^{2}$ ) (2011). Antenatal care with nutrition and physical activity recommendations was carried out in accordance with existing Ukrainian guidelines (2011).

Prepregnancy weight status of patients was assessed with BMI $\left(\mathrm{kg} / \mathrm{m}^{2}\right)$ calculated from prepregnancy weight and height. Information on the body weight of women before pregnancy was obtained by interviewing patients and medical records. Anthropometry was performed at the first prenatal visit $(9.8 \pm 1.4$ weeks), and before the delivery. Patients were weighed on the electronic scale to the nearest $0.1 \mathrm{~kg}$. Height was measured using a digital stadiometer with an accuracy of $1.0 \mathrm{~cm}$. GWG was evaluated by the difference between the weight before delivery and prepregnancy. The results were compared to the recommended weight gain for women with normal BMI $(11.5-16.0 \mathrm{~kg})$ according to the recommendations of the Institute of Medicine in the USA (2009) and the Order of the Ministry of Health of Ukraine No 417 (2011).

Study of the Gln233Arg polymorphism of the LEPR gene was performed at the state institution "Reference Center for Molecular Diagnostics of the Ministry of Health of Ukraine" (Kyiv). Genomic DNA for molecular-genetic studies was isolated from peripheral blood using a commercial "innuPREP Blood DNA Mini Kit" test system (Analytik Jena, Germany) using centrifuge filters. For the determination of the polymorphic variants of the LEPR Q223R (668A/G, rs1137101), modified protocols were used using the polymerase chain reaction method and the subsequent analysis of polymorphism (Mahmoudi \& Alavicheh, 2015). Visualization was done by using the Vitran computer program (Fig. 1). The genotype AA was recorded in the presence of DNA fragments with a length of 416 p.n., genotype GG-fragments with a length of 291 and 125 p.n., and genotype AG-fragments length 416, 291 and 125 p.n.

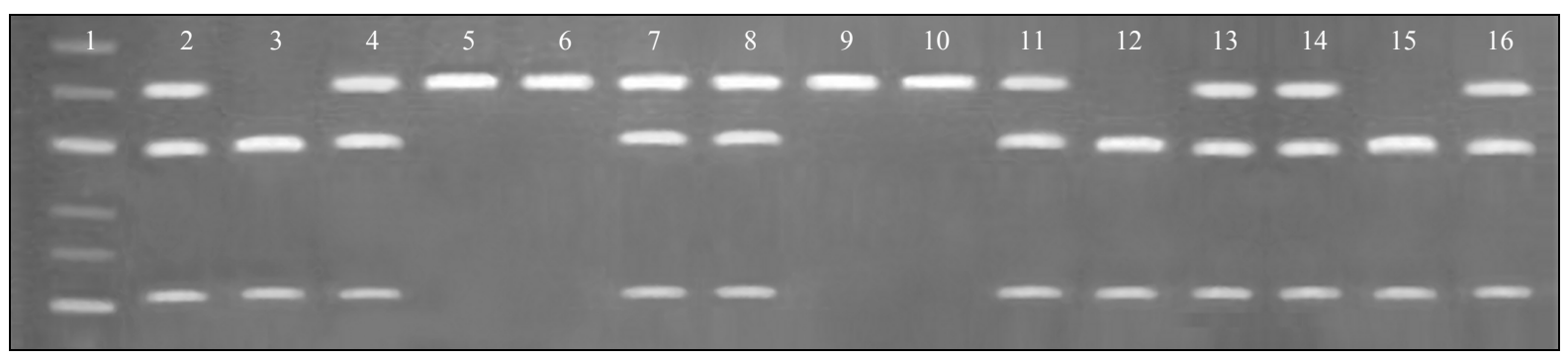

Fig. 1. Electrophoregram of the distribution of DNA fragments of the gene LEPR Q223R: specimen 1 is a molecular weight marker; specimens 5, 6, 9, 10 - genotype AA; 2, 4, 7, 8, 11, 13, 14, 16-genotype AG; specimens 3, 12, 15 - genotype GG

Lipid profile was established on the basis of the laboratory determination of the concentration of triglycerides ( $\mathrm{TG}$ - Triglycerides $\mathrm{SpL}$ (SpinLab LLC, Ukraine)), total cholesterol (TC - Cholesterol SPL (LLC SpinLab, Ukraine)), high lipoprotein, low and very low density (HDL, LDL, VLDL - "HDL-Cholesterol SPL" (LLC "SpinLab", Ukraine)). To study the carbohydrate status, the level of blood glucose in blood plasma was determined by standard methods (Dolgov, 2013), blood insulin content in blood serum by the immune enzyme method (Insulin Test System-2425-300 (Monobind Inc., USA)) with the following calculation of the index of immunoreactivity of HOMO-IR by the formula: glucose $(\mathrm{mmol} / \mathrm{L}) \mathrm{x}$ insulin $(\mu \mathrm{M} / \mathrm{mL}) / 22.5$. Quantitative determination of leptin in serum was performed by ELISA Kit (CAN-L-4260, Canada). The examination was conducted in the first and third trimesters of preg- nancy. The results were statistically analyzed using Statistica 6.0 program pack (StatSoft Inc.,USA). The parameters are presented as mean arithmetic value, mean standard deviation $(\mathrm{x} \pm \mathrm{SD})$. For comparison of genotype and allele frequencies between the groups (normal, inadequate and excessive weight) odds ratio (OR), 95\% confidence interval (CI), and P-value were obtained. The differences between the selections were considered statistically reliable at $\mathrm{P}<0.05$ (Tukey's test).

\section{Results}

The analysis of Gln223Arg polymorphism of the LEPR gene showed that $20.6 \%$ patients were with AA genotype, $50.5 \%$ - AG genotype, and $28.9 \%$ - GG genotype. We identified all three genotypes AA, 
AG and GG in the women and the frequencies of the $\mathrm{A}$ and $\mathrm{G}$ alleles in our study were within the limits of the typical Ukrainian population (Ghali et al, 2012).

Prepregnancy weight among AA pregnant women was $56.2 \pm 6.5$ $\mathrm{kg}$, BMI $20.7 \pm 0.8 \mathrm{~kg} / \mathrm{m}^{2}$, among carriers of AG alleles $55.8 \pm 5.8 \mathrm{~kg}$, BMI $20.8 \pm 1.7 \mathrm{~kg} / \mathrm{m}^{2}$, and among GG-genotype women $56.3 \pm 5.0 \mathrm{~kg}$, BMI $20.6 \pm 1.3 \mathrm{~kg} / \mathrm{m}^{2}$, which were not significantly different $(\mathrm{P}>0.05)$. We diagnosed that GWG in late pregnancy in homozygous A-allele carriers was $10.7 \pm 2.6 \mathrm{~kg}$, in women with AG-genotype $15.6 \pm 3.0 \mathrm{~kg}$, and in the homozygous G-allele carriers $18.6 \pm 2.9 \mathrm{~kg}$ (Fig. 2).

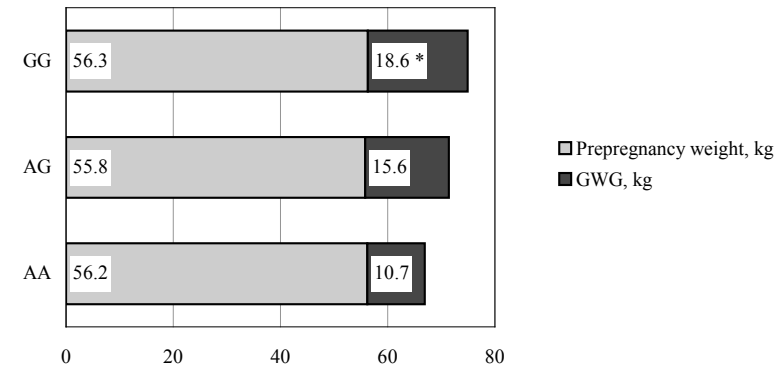

Fig. 2. The level of gestational weight gain $(\mathrm{kg})$ in pregnant women, depending on the Gln223Arg polymorphism of the LEPR gene: GWG-gestational weight gain; $\mathrm{n}=97$

Thus, we diagnosed that GWG in the group of patients with gene LEPR GG polymorphism was significantly, by 1.7 times, higher compared to pregnant women with AA-genotype $(\mathrm{P}<0.05)$. In the group of pregnant women with AG-genotype, GWG was also higher in comparison to AA-genotype, but the difference was not statistically significant $(\mathrm{P}>0.05)$. Also, no probable difference in weight gain was found in heterozygous carriers and homozygous G-allele carriers $(\mathrm{P}>0.05)$. Comparison of genotypes of LEPR gene polymorphism in pregnant women with different GWG is presented in Table 1.

\section{Table 1}

Comparison of the Gln223Arg (Q223R) polymorphism

of the LEPR gene in pregnant women with different gestational weight gain $(\mathrm{x} \pm \mathrm{SD})$

\begin{tabular}{crrrcrc}
\hline Genotype of & \multicolumn{2}{c}{ Normal GWG } & \multicolumn{2}{c}{ Inadequate GWG } & \multicolumn{2}{c}{ Excessive GWG } \\
\cline { 2 - 7 } LEPR gene & \multicolumn{1}{c}{$\mathrm{n}$} & $\%$ & $\mathrm{n}$ & $\%$ & $\mathrm{n}$ & $\%$ \\
\hline $\mathrm{AA}$ & 10 & $30.3 \pm 8.0$ & 6 & $31.6 \pm 10.7$ & 4 & $8.9 \pm 4.2^{\#}$ \\
$\mathrm{AG}$ & 17 & $51.5 \pm 8.7$ & 10 & $52.6 \pm 11.5$ & 22 & $48.9 \pm 7.5^{*}$ \\
GG & 6 & $18.2 \pm 6.7$ & 3 & $15.8 \pm 8.4$ & 19 & $42.2 \pm 7.4^{* \#}$ \\
\hline
\end{tabular}

Notes: ${ }^{\#}$ - compared to women with normal GWG $(\mathrm{P}<0.05), *$ - compared to women-carriers of AA genotype $(\mathrm{P}<0.05)$; GWG - gestational weight gain.

It was found that the frequency of Gln223Arg polymorphism of the LEPR gene in pregnant women with recommended and insufficient GWG was not statistically significant $(\mathrm{P}>0.05)$ : one half were heterozygous carriers of AG alleles, about one third were individuals with AA genotype and $18.2 \pm 6.7 \%$ and $15.8 \pm 8.4 \%$ were GG genotype carriers, respectively. However, the distribution of genotypes in patients with excessive GWG significantly differed. Thus, the proportion of AAhomozygotes in this group was significantly minimal $8.9 \pm 4.2 \%(\mathrm{P}<$ $0.001)$ and was (OR $0.2,95 \% \mathrm{Cl} 0.1-0.8, \mathrm{P}<0.05)$ lower compared to pregnant women of a similar genotype with normal body weight gain. The percentage of subjects with pathological GG homozygotes in this group was 3 times (OR 3.0, 95\% Cl 1.1-9.1, $\mathrm{P}<0.05$ ) higher compared to patients with the recommended weight gain.

To study the role of the genetic predisposition for excessive GWG, we investigated the interaction of the polymorphism of the leptin receptor gene with metabolic disorders during pregnancy.

While studying the dynamics of laboratory parameters of lipid metabolism in pregnant women, depending on LEPR gene Gln223Arg polymorphism, we established the correspondence of lipid concentration at the beginning of pregnancy with the reference value and the $a b-$ sence of a significant difference in patients with AA, AG and GG-genotype $(\mathrm{P}>0.05)$ (Table 2$)$.
In late pregnancy, the levels of atherogenic lipids were significantly increased in all patients compared to the early terms $(\mathrm{P}<0.05)$. Thus, in the third trimester, triglyceride levels were significantly increased by 1.5 times, $\mathrm{TC}-1.2$ times, $\mathrm{LDL}-1.3$ times, VLD - 2.2 times (in all cases, $\mathrm{P}<0.05$ ) in pregnant women with LEPR GG polymorphism, compared to homozygous A-carriers allele.

\section{Table 2}

Serum blood levels of lipid metabolism parameters in pregnant women depending on Gln223Arg polymorphism of the LEPR gene $(\mathrm{x} \pm \mathrm{SD})$

\begin{tabular}{lcccccc}
\hline \multirow{2}{*}{$\begin{array}{l}\text { Indi- } \\
\text { cations }\end{array}$} & \multicolumn{2}{c}{$\mathrm{AA}, \mathrm{n}=20$} & \multicolumn{2}{c}{$\mathrm{AG}, \mathrm{n}=49$} & \multicolumn{2}{c}{$\mathrm{GG}, \mathrm{n}=28$} \\
& $\begin{array}{c}\mathrm{I} \\
\text { trimester }\end{array}$ & $\begin{array}{c}\mathrm{III} \\
\text { trimester }\end{array}$ & $\begin{array}{c}\mathrm{I} \\
\text { trimester }\end{array}$ & $\begin{array}{c}\mathrm{III} \\
\text { trimester }\end{array}$ & $\begin{array}{c}\mathrm{I} \\
\text { trimester }\end{array}$ & $\begin{array}{c}\mathrm{III} \\
\text { trimester }\end{array}$ \\
\hline $\mathrm{TG}$, & $1.17 \pm$ & $2.08 \pm$ & $1.03 \pm$ & $2.12 \pm$ & $1.27 \pm$ & $3.09 \pm$ \\
$\mathrm{mmol} / \mathrm{L}$ & 0.31 & $0.32^{*}$ & 0.26 & $0.48^{*}$ & 0.27 & $0.25^{* \#}$ \\
$\mathrm{TC}$, & $4.83 \pm$ & $5.63 \pm$ & $4.88 \pm$ & $6.08 \pm$ & $4.88 \pm$ & $6.58 \pm$ \\
$\mathrm{mmol} / \mathrm{L}$ & 0.22 & 0.14 & 0.17 & $0.42^{*}$ & 0.17 & $0.38^{* \#}$ \\
$\mathrm{HDL}$ & $1.58 \pm$ & $2.13 \pm$ & $1.65 \pm$ & $1.79 \pm$ & $1.60 \pm$ & $1.60 \pm$ \\
$\mathrm{mmol} / \mathrm{L}$ & 0.13 & 0.27 & 0.12 & 0.18 & 0.16 & 0.14 \\
$\mathrm{LDL}$, & $2.40 \pm$ & $3.03 \pm$ & $2.41 \pm$ & $3.29 \pm$ & $2.47 \pm$ & $3.76 \pm$ \\
$\mathrm{mmol} / \mathrm{L}$ & 0.18 & $0.14^{*}$ & 0.14 & $0.17 *$ & 0.22 & $0.17^{* \#}$ \\
$\mathrm{VLDL}$, & $0.31 \pm$ & $0.62 \pm$ & $0.32 \pm$ & $0.93 \pm$ & $0.34 \pm$ & $1.27 \pm$ \\
$\mathrm{mmol} / \mathrm{L}$ & 0.14 & 0.16 & 0.16 & 0.29 & 0.15 & $0.28^{* \#}$ \\
$\mathrm{Leptin}$, & $14.16 \pm$ & $23.16 \pm$ & $13.94 \pm$ & $27.62 \pm$ & $13.67 \pm$ & $31.86 \pm$ \\
$\mathrm{ng} / \mathrm{mL}$ & 1.06 & $3.00 *$ & 0.82 & $4.12^{*}$ & 0.85 & $3.10^{* \#}$ \\
\hline
\end{tabular}

Notes: * - compared to the 1 st trimester $(\mathrm{P}<0.05) ;{ }^{*}$ - compared to AA-genotype carriers $(\mathrm{P}<0.05)$; TG - triglycerides; TC - total cholesterol; HDL - high lipoprotein; LDL - low density lipoprotein; VLDL - very low density lipoprotein.

The analysis of the association of the LEPR gene polymorphism with the serum leptin levels showed that the presence of the genotype GG is associated with a significantly higher by 1.4 times $(\mathrm{P}<0.05)$ concentration of this adipocytokine compared to AA-genotype carriers.

We observed that pregnant women with excessive GWG inherited the GG allele of the LEPR gene associated with higher levels of hypertriglyceridemia, hypercholesterolemia and higher concentrations of LDL and LDL compared to carriers of AA and AG alleles (in all cases $\mathrm{P}<$ $0.05)$. A strong positive correlation was found between the serum leptin concentration and GWG in the third trimester $(r=0.86, \mathrm{P}<0.001)$ (Fig. 3). In the group of individuals with excessive GWG, the presence of GGalleles of the LEPR gene was accompanied by a higher level of hyperleptinemia, compared to carriers of AA-genopyte $(\mathrm{P}<0.05)$. Obviously, in pregnant women with LEPR Gln223Arg gene GG-polymorphism, excessive hyperleptinemia is based on leptin resistance, which leads to a decrease in the absorption of glucose by tissues, fat oxidation, signals to increase the food intake, and to a pathological GWG.

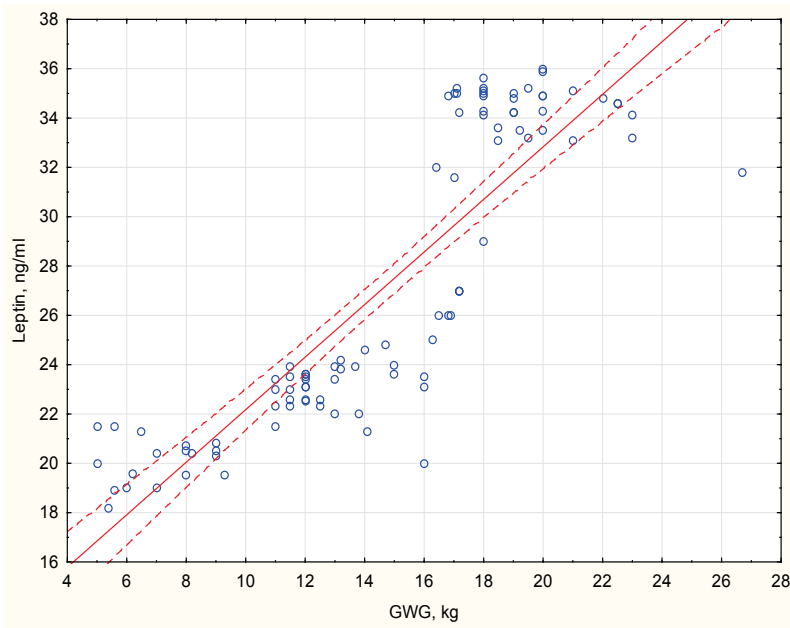

Fig. 3. Relationship of the plasma leptin concentration and gestational weight gain in the third trimester: GWG-gestational weight gain, $n=97$

Results of the LEPR Gln223Arg gene polymorphism study revealed no significant differences in serum glucose level, insulin level and 
HOMO-IR index in women with AA and AG genotype (both of them $\mathrm{P}>0.05)($ Table 3$)$.

Table 3

Carbohydrate metabolism parameters in pregnant women depending on Gln223Arg polymorphism of the LEPR gene $(\mathrm{x} \pm \mathrm{SD})$

\begin{tabular}{lcccccc}
\hline \multirow{2}{*}{ Indications } & \multicolumn{2}{c}{$\mathrm{AA}, \mathrm{n}=20$} & \multicolumn{2}{c}{$\mathrm{AG}, \mathrm{n}=49$} & \multicolumn{2}{c}{$\mathrm{GG}, \mathrm{n}=28$} \\
\cline { 2 - 7 } & $\begin{array}{c}\mathrm{I} \\
\text { trimester }\end{array}$ & $\begin{array}{c}\mathrm{III} \\
\text { trimester }\end{array}$ & $\begin{array}{c}\mathrm{I} \\
\text { trimester }\end{array}$ & $\begin{array}{c}\mathrm{III} \\
\text { trimester }\end{array}$ & $\begin{array}{c}\mathrm{I} \\
\text { trimester }\end{array}$ & $\begin{array}{c}\mathrm{III} \\
\text { trimester }\end{array}$ \\
\hline Glucose, & $4.29 \pm$ & $3.66 \pm$ & $4.38 \pm$ & $4.18 \pm$ & $4.50 \pm$ & $4.79 \pm$ \\
$\mathrm{mmol} / \mathrm{L}$ & 0.26 & 0.31 & 0.27 & 0.47 & 0.26 & $0.38^{\#}$ \\
$\mathrm{Insulin}$, & $8.14 \pm$ & $8.38 \pm$ & $8.78 \pm$ & $10.65 \pm$ & $9.48 \pm$ & $12.57 \pm$ \\
$\mu \mathrm{U} / \mathrm{mL}$ & 0.93 & 1.31 & 0.93 & 1.81 & 0.87 & $1.61^{\#}$ \\
$\mathrm{HOMO}-\mathrm{IR}$ & $1.62 \pm$ & $1.47 \pm$ & $1.71 \pm$ & $2.03 \pm$ & $1.70 \pm$ & $2.60 \pm$ \\
index & 0.22 & 0.38 & 0.21 & 0.57 & 0.20 & $0.4^{* \#}$ \\
\hline
\end{tabular}

Notes: * - compared to the Ist trimester $(\mathrm{P}<0.05)$; \#- compared to women AAgenotype carriers $(\mathrm{P}<0.05)$.

However, at the end of pregnancy, the concentrations of glucose by 1.3 times, insulin by 1.5 times, and HOMO-IR index by 1.7 times were significantly higher in the homozygous $\mathrm{G}$-carriers as compared to the AA-genotype pregnant women (in all cases $\mathrm{P}<0.01$ ). The genotype GG was associated with a statistically higher insulin resistance index by 1.5 times before delivery compared to the first trimester $(\mathrm{P}<0.05)$, which was not noted in other groups. The analysis of laboratory parameters of carbohydrate metabolism in pregnant women with excessive GWG showed that the inheritance of the GG allele of the LEPR gene polymorphism is associated with hyperglycemia, hyperinsulinemia, and higher levels of HOMO-IR index compared to carriers of AA alleles (in all cases $\mathrm{P}<0.05$ ). In our research, the significant association of the LEPR Gln223Arg polymorphism and the level of GWG has been proved. According to our study, the inheritance of pathological homozygotes GG increases the risk of excessive body weight more than 7 times (OR 7.5, 95\% Cl 2.3-24.5, $\mathrm{P}<0.001$ ) compared to carriers of the AA genotype.

\section{Discussion}

This study has two main findings. First, we found that the Gln223Arg polymorphism of the leptin receptor gene is associated with metabolic shifts in pregnancy. Second, we observed a significant interaction between the polymorphism of LEPR gene and the weight gain during pregnancy. Moreover, as far as we know, this is the first study aimed to evaluate GWG according to the polymorphism of the LEPR gene in pregnant women with normal prepregnancy BMI, normotensive and non-diabetes mellitus. We have proved that the absence of statistical difference between lipid and carbohydrate metabolism in early pregnancy and reliable signs of hyperlipidemia, hyperglycemia, hyperleptinemia and insulin resistance in the third trimester in the presence of polymorphism of the LEPR gene, which are clinically manifested by excessive GWG, indicate a high risk of metabolic decompensation and forms the pathogenetic basis of the energy insufficiency and reduced adaptive capacity of the mother to gestation.

Leptin regulates energy and nutrition through interaction with its own receptors in tissues. One of the most important target tissues is the central nervous system, which regulates appetite and energy consumption through the $\mathrm{Ob}-\mathrm{Rb}$ receptor located in the hypothalamus. The absence of proper interaction of leptin with its own receptor in the hypothalamus disrupts the signal transmission of leptin and results in an imbalance of energy consumption, which leads to overweight (Jing et al., 2016). Authors argue that the cause of obesity is not the defects in leptin, but that the problem lies in the resistance to leptin. Leptin resistance can occur due to defects in the gene itself (polymorphism, lipoprotection, voltage of the endoplasmic reticulum), as well as post receptor defect in hormone action (inflammatory reactions), which may interfere with intracellular transport of messages (Lopez et al., 2016; Daghestani et al., 2019). In this study we also have proved that in pregnant women with LEPR Gln223Arg gene GG-polymorphism, excessive serum hyperleptinemia is based on leptin resistance due to modified transcriptional activity of the LEPR gene. In the case-control study published by Olza et al. (2017), the authors demonstrate that the interaction between leptin and insulin in the hypothalamus via appropriate receptors contributes to changes in the expression of the hypothalamic neuropeptides that regulate the energy balance and glucose metabolism. Experimental studies by Berglund et al. (2012) have shown that the reintroduction of the leptin receptors in the hypothalamus of LEPR null mice reduces obesity in different degrees and through different actions. When LEPR were reintroduced in the pro-opiomelanocortin (POMC) neurones, which usually express LEPR, and other hypothalamic regions where LEPR expression has been associated with the regulation of food intake, the animals showed a discrete reduction in body weight and adiposity due to an increase in energy expenditure and also an improvement in the glucose and lipid metabolisms. The authors noted that the improvement in glucose levels and insulin sensitivity was independent of body weight, suggesting that leptin signalling in POMC neurones has a role in regulating glucose homoeostasis and that this regulatory role is not influenced by adiposity. In fact, it has been described that leptin participates in regulating glucose homeostasis and insulin sensitivity by signalling pathways, which include: Janus kinase (JAK), phosphatidylinositol 3'kinase (PI3K) and extracellular signal-regulated kinase (ERK), which confirms the results of another study (Paz-Fhilo et al., 2012). Thus, the association found in this study between Gln223Arg LEPR and excessive GWG may be also related to a lower expression of LEPR, which could derive from insulin resistance through mechanisms such as those explained above. Our results demonstrate that leptin-based weight control during pregnancy is different from non-pregnant women, who have a CNS-related linkage, which is classically attributed to this hormone.

Leptin receptors are widely expressed in peripheral tissues of the human body, and are regulators of metabolic control. Recently published research by Yang et al. (2018) suggests the presence of leptin receptors on pancreatic islets cells that determine the inhibitory effect of leptin on insulin secretion through the formation of the OBRb / Janus kinase 2 complex (JAK2). According to the authors, phosphorylation of JAK2 defines modulation of the activity of insulin receptors and mitogen activated protein kinase (MAPK), which highlights the important role of leptin receptors in regulating the sensitivity of target cells to insulin, metabolism control and energy metabolism. Results in this study add knowledge on this issue by showing a significant difference in leptin levels between women with AA, AG, and genotype of LEPR.

Leptin receptor plays an essential role in the physiological effects of leptin. Although some studies have described very high circulating levels of leptin in carriers of LEPR mutations, others have not. Sulaieva et al. (2018) demonstrated the gender-associated nature of the link between Gln223Arg polymorphism of LEPR and overweight, signs of dysfunction of beta cells of the insulin apparatus of the pancreas, secretory activity of adipose tissue, and the spectrum of produced adipokines in 244 Ukrainian patients. The authors have proved that in women, the presence of the allele $\mathrm{G}$ (homozygotes GG and heterozygotes AG) was associated with excessive BMI, the development of insulin resistance, an increase in atherogenic lipids. In contrast, in our study, overweight was determined predominantly in G-homozygous women carriers.

A statistically significant association between LEPR Gln223Arg polymorphism and elevated serum levels of leptin, glucose, and insulin resistance was found by Suriyaprom et al. (2014) in women with metabolic syndrome. At the same time, Farzam et al. (2017) did not show a reliable association between G-allele carriers and GG-polymorphism of leptin receptors with BMI in the Iranian population. They suggested that during pregnancy, the supply of fetal support was compensated by the placental expression of leptin. Thus, the leptin gene and leptin receptor gene polymorphisms did not significantly affect the increased concentration of maternal leptin. The results of Manriquez et al. (2018) suggest that polymorphisms at LEPR may be useful biomarkers of obesity-related cardiometabolic alterations in the Southern Chilean population. Thus, it can be assumed that such controversial conclusions may be due to the different genetic background of the populations, as well as to the small sample sizes used (Olza et al., 2017; Manriquez et al., 2018). Several factors have been proposed to explain the mechanisms involved in the development of insulin resistance and include obesity, inflammation, hyperlipidemias and others. We can propose that one of the factors 
could be Gln223Arg polymorphism in the LEPR gene. Our study demonstrates that the inheritance of pathological homozygotes GG increases the risk of excessive body weight by more than 7 times $(\mathrm{P}<$ 0.001) compared to carriers of the AA-genotype.

Nevertheless, the results we have received confirm the involvement of the LEPR Gln223Arg polymorphism in determining the predisposition to development of metabolic shifts during excessive GWG typical to obesity and type 2 diabetes (Carlhäll et al., 2016; Li et al., 2017).

In the present study, we demonstrated that the Gln223Arg polymorphism of the LEPR gene, associated with lipid and carbohydrate metabolism, has a direct effect on the weight gain during pregnancy, the risk of postpartum weight retention, and the development of overweight and obesity after delivery. In our opinion, excessive GWG can be seen as a marker of the mother's genotype and genetic predisposition to the development of metabolic diseases after delivery. Subsequent studies should be aimed at studying the association of LEPR Gln233Arg polymorphism with the risk of development of obstetric and perinatal complications.

Our study has several strengths and limitations, which should be mentioned. The main strengths are the high quantity of analysed biomarkers and molecular-genetic studies. The limitations include the relatively small sample size for the genetic association study, which requires further validation in independent and larger populations.

\section{Conclusion}

Thus, our results allow us to expand the current knowledge about the role of the polymorphism of LEPR Gln223Arg in the genesis of metabolic disorders with pathological gestational weight gain. Inheritance of pathological homozygotes GG is associated with hyperlipidemia, leptin resistance with high serum leptin level, increased tissue resistance to insulin, which is especially pronounced in excessive GWG. Thus, studying the gene polymorphisms among the population of Ukraine is promising as it helps to highlight the mechanisms of implementation of hereditary predisposition to metabolic disorders and, as a consequence of the pathology of gestational and postpartum periods.

\section{References}

Berglund, E. D., Vianna, C. R., Donato, J., Kim, M. H., Chuang, J. C., Lee, C. E., Lauzon, D. A., Lin, P., Brule, L. J., \& Scott, M. M. (2012). Direct leptin action on POMC neurons regulates glucose homeostasis and hepatic insulin sensitivity in mice. Journal of Clinical Investigation, 122, 1000-1009.

Costa, M. A. (2016). The endocrine function of human placenta: An overview. Reproductive Biomedicine Online, 32(1), 1443.

Daghestani, M., Purohit, R., Daghestani, M., Daghistani, M., \& Warsy, A. (2019). Molecular dynamic (MD) studies on Gln233Arg (rs1137101) polymorphism of leptin receptor gene and associated variations in the anthropometric and metabolic profiles of Saudi women. PLoS One, 14(2), e0211381.

Deren, K., Nyankovskyy, S., Nyankovska, O., Łuszczki, E., Wyszyńska, J., Sobolewski, M., \& Mazur, A. (2018). The prevalence of underweight, overweight and obesity in children and adolescents from Ukraine. Scientific Reports, 8, e3625.

Devlieger, R., Benhalima, K., Damm, P., Van Assche, A., Mathieu, C., Mahmood, T., Dunne, F., \& Bogaerts, A. (2016). Maternal obesity in Europe: Where do we stand and how to move forward? European Journal of Obstetrics and Gynecology and Reproductive Biology, 201, 203-208.

Farpour-Lambert, N. J., Louisa, J. E., Martinez de Tejada, B., \& Scott, C. (2018). Obesity and weight gain in pregnancy and postpartum: An evidence review of lifestyle interventions to inform maternal and child health policies. Frontiers in Endocrinology (Lausanne), 9, 546-552.

Farzam, F., Mahmazi, S., \& Nasseryan, J. (2017). Association of leptin receptor gene Gln223Arg and lys109Arg polymorphisms with obesity and overweight in an iranian young population. Gene Cell Tissue, 4(3), e57937.

Ghali, Z. H., Ahmed, I. H., Gorshunska, M. Y., Pochernyaev, A. K., \& Atramentova, L. A. (2012). Structure of Ukrainian population on SNP rs1137101 of leptin receptor gene LEPR. Visnyk of V. N. Karazin Kharkiv National University, Biology, 15, 94-98.

Goldstein, R. F., Abell, S. K., Ranasinha, S., Misso, M. L., Boyle, J. A., Harrison, C. L., Black, M. H., Li, N., Hu, G., Corrado, F., Hegaard, H., Kim, Y. J., Haugen, M., Song, W. O., Kim, M. H., Bogaerts, A., Devlieger, R., Chung,
J. H., \& Teede, H. J. (2018). Gestational weight gain across continents and ethnicity: Systematic review and meta-analysis of maternal and infant outcomes in more than one million women. BMC Medicine, 16(1), 153-167.

Hales, C. M., Carroll, M. D., Fryar, C. D., \& Ogden, C. L. (2017). Prevalence of obesity among adults and youth: United States, 2015-2016. NCHS Data Brief, 288, 1-8.

Jing, X., Ou, C., Chen, H., Wang, T., Xu, B., Lu, S., \& Zhu, B. (2016). Electroacupuncture reduces weight gain induced by rosiglitazone through PPARgamma and leptin receptor in CNS. Evidence - Based Complementary and Alternative Medicine, 2, 1-12.

Li, Y. Y., Wang, H., Yang, X. X., Wu, J. J., Geng, H. Y., Kim, H. J., Yang, Z. J., \& Wang, L. S. (2017). LEPR gene Gln223Arg polymorphism and type 2 diabetes mellitus: A meta - analysis of 3,367 subjects. Oncotarget, 37(8), e61927.

Logan, C. A., Bornemann, R., Koenig, W., Reister, F., Walter, V., Fantuzzi, G., Weyermann, M., Brenner, H., Genuneit, J., \& Rothenbacher, D. (2017). Gestational weight gain and fetal-maternal adiponectin, leptin, and CRP: Results of two birth cohorts studies. Scientific Reports, 2(7), e41847.

Lopez, M. (2016). Hypothalamic leptin resistance: From BBB to BBSome. PLoS Genetics, 12(5), e1005980.

Mahmoudi, R., \& Alavicheh, B. N. (2015). Polymorphisms of leptin (2548 G/A) and leptin receptor (Q223R) genes in iranian women with breast cancer. International Journal of Genomics, 6, e132720.

Manriquez, V., Aviles, J., Salazar, L., Saavedra, N., Seron, P., Lanas, F., Fajardo, C. M., Hirata, M. H., Hirata, R. D. C., \& Cerda, A. (2018). Polymorphisms in genes involved in the leptin-melanocortin pathway are associated with obesity-related cardiometabolic alterations in a Southern Chilean population. Molecular Diagnosis and Therapy, 22(1), 101-113.

Maymó, J. L., Pérez Pérez, A., Gambino, Y., Calvo, J. C., Sánchez-Margalet, V., \& Varone, C. L. (2011). Review: Leptin gene expression in the placentaregulation of a key hormone in trophoblast proliferation and survival. Placenta, 32(2), 146-153.

Napso, T., Yong, H. E. J., Lopez-Tello, J., \& Sferruzzi-Perri, A. N. (2018). The role of placental hormones in mediating maternal adaptations to support pregnancy and lactation. Frontiers in Physiology, 9, e1091.

Olza, J., Rupérez, A. I., Gil-Campos, M., Leis, R., Cañete, R., Tojo, R. Á., \& Aguilera, M. (2017). Leptin receptor gene variant rs11804091 is associated with BMI and insulin resistance in Spanish female obese children: A casecontrol study. International Journal of Molecular Sciences, 18(8), e1690.

Paz-Fhilo, G., Mastronardi, C., \& Franco, C. (2012). Leptin: Molecular mechanisms, systemic pro-inflammatory effects, and clinical implications. Arquivos Brasileiros de Endocrinologia and Metabologia, 56, 597-607.

Pérez-Pérez, A., Toro, A., Vilariño-Garcia, T., Guadix, P., Maymó, J., Dueñas, J. L., Varone, C., \& Sánchez-Margalet, V. (2019). Leptin protects placental cells from apoptosis induced by acidic stress. Cell and Tissue Research, 375, 733-742.

Sámano, R., Martínez-Rojano, H., Chico-Barba, G., Godínez-Martínez, E., Sánchez-Jiménez, B., Montiel-Ojeda, D., \& Tolentino, M. (2017). Serum concentration of leptin in pregnant adolescents correlated with gestational weight gain, postpartum weight retention and newborn weight/length. Nutrients, 9(10), e1067.

Sara, C., Bladh, M., Brynhildsen, J., Claesson, I.-M., Josefsson, A., Sydsjö, G., Thorsell, A., \& Blomberg, M. (2016). Maternal obesity (Class I-III), gestational weight gain and maternal leptin levels during and after pregnancy: A prospective cohort study. BMC Obesity, 3, 28-38.

Sulaieva, O., Belemets, N., Goncharov, S., \& Dosenko, V. (2018). Gender differences in the relation between Q223R polymorphism of leptin receptor gene and risk of type 2 diabetes mellitus. Clinical Endocrinology and Endocrine Surgery, 64(4), 29-34 (in Ukrainian).

Sulaieva, O., Chereshneva, Y., Kartashkina, N., Ivanova, M., \& Tsomartova, D. (2018). Secretory function of white adipose tissue and adipokines: Biological effects and clinical significance. Georgian Med News, 274, 116-124 (in Russian).

Suriyaprom, K., Tungtrongchitr, R., \& Thawnasom, K. (2014). Measurement of the levels of leptin, BDNF associated with polymorphisms LEP G2548A, LEPR Gln223Arg and BDNF Val66Met in Thai with metabolic syndrome. Diabetology and Metabolic Syndrome, 6, 6-13.

Tessier, D. R., Ferraro, Z. M., \& Gruslin, A. (2013). Role of leptin in pregnancy: Consequences of maternal obesity. Placenta, 34(3), 205-211.

Tsai, P-J. S., Davis, J., \& Bryant-Greenwood, G. (2015). Systemic and placental leptin and its receptors in pregnancies associated with obesity. Reproductive Sciences, 22(2), 189-197.

Yang, Y., \& Niu, T. (2018). A meta-analysis of associations of LEPR Q223R and K109R polymorphisms with type 2 diabetes risk. PLoS One, 13(1), e 0189366. 